\title{
Report on the Distribution of the Social Determinants of Health and Health Equity in a Forensic Psychiatry Program
}

\author{
Samantha Perrotta, ${ }^{1}$ Bruno Losier ${ }^{2,3}$ \\ ${ }^{1}$ Department of Health Aging and Society, McMaster University, Hamilton, Canada; ${ }^{2}$ Department of Psychiatry and \\ Neurosciences, McMaster University, Hamilton, Canada; ${ }^{3}$ Forensic Psychiatry Program, St. Joseph's Healthcare \\ Hamilton, Hamilton, Canada
}

\begin{abstract}
The social determinants of health are important factors that shape a person's wellbeing, life expectancy, and quality of life. The environments in which people live, work, and play are paramount in determining their overall health. As such, viewing health as an outcome, not only of individual choices and biomedical factors but also of socioenvironmental influences, can be an important lens to guide health-care practice. This report examined the social determinants of health of people admitted to inpatient units in a forensic psychiatry program in a major Canadian urban centre. Twenty health variables were collected from the Resident Assessment InstrumentMental Health form. A deprivation scale was created to understand social and material inequality on a gradient. Findings showed that those surveyed had high rates of poor social determinant of health factors, such as low educational attainment, insecure housing, and lack of secure employment before their admission to the program. Chi-square tests showed associations between material deprivation, race, and comorbidity status. The findings may influence a multisectorial approach to mental illness prevention, management, and recovery practices.
\end{abstract}

Key Words: forensic mental health, social determinants of health, health equity

Even in the most affluent societies, people in lower socioeconomic status groups experience shorter lifespans [1]. People who are more socially and economically deprived have higher rates of stress, mental illness, cardiac disease, and other chronic conditions, which lead to poorer quality of life and lowered life expectancies [2]. This health disparity between those who are more and less socially and economically deprived is referred to as health inequity. Health inequities are considered avoidable and are shaped by social structures and policies [3].
Social structures and the environments in which people live, work, and play are powerful factors in shaping health and are known as social determinants of health [3]. The social determinants of health influence health equity and are identified by the Canadian Public Health Association [4] to include:

- income and income distribution

- education

- unemployment and job security

- employment and working conditions

- early childhood development

- food insecurity 
- housing

- social exclusion or social safety network

- health services

- Indigenous status

- gender

- race

- disability

The social determinants of health are important to understand and apply in health-care environments. As the World Health Organization indicates, they account for between $30 \%$ and $55 \%$ of health outcomes and are more important than lifestyle choices and health interventions in affecting health [3]. This influence can be observed in mental illness rates, which are more prevalent in lower socioeconomic status groups [5]. Moreover, mental illness is associated with increased mortality in comparison to the general population, largely due to preventable illnesses [6]. This will also be addressed in this report. Social and environmental factors, including race, ethnicity, early childhood trauma, lowered ability to perform in education, inability to find or participate in stable employment, lower income, unequal access to greenspace and healthy foods, poor social relationships, and more can influence or exacerbate mental illness and other chronic conditions [5]. The social determinants of health will be carried forward as the guiding framework of this report. It recognizes that health status is influenced by a person's broader social context and can be used to understand their need for support from social institutions, such as a forensic psychiatry program (FPP) and others.

\section{Note on Language}

As models of health care in a Canadian context shift toward person-centred care (PCC), we followed language aligned with PCC philosophy for this article. PCC is associated with improved care, better health outcomes, and enhanced feelings of dignity and comfort [7]. It recognizes the person before their disease and acknowledges them as active and autonomous agents in their care [8]. In the mental health literature, there is opposition for the term patient as it implies one is a passive recipient of care [8]. As such, we opted to describe those admitted to the FPP as people or individuals.

\section{Application to Forensic Population}

For people who use mental health services, histories of poverty, neglect, and abuse, as well as psychological, biological, and genetic factors are common and believed to have contributed to their mental illness. While people with a mental illness are overrepresented in the criminal justice system, this diagnosis alone is not linked to an increased likelihood of criminal behaviour $[9,10]$. The most important predictors associated with high rates of criminal behaviour and recidivism in this population include antisocial personality disorders, psychopathy, neurocognitive brain impairment (associated with impulsivity), substance abuse, having antisocial associates, and living in chaotic environments with limited social supports [10]. Socially disorganized communities tend to support substance abuse and violence, which can exacerbate criminogenic characteristics for those with a mental health concern.

While recovery efforts improve a person's wellbeing, given the low-income status of those in the criminal justice system, people often must return to similar environments that led them to criminal activity initially [11]. Those who come into contact with the law generally have been exposed to numerous social and environmental factors influencing criminal behaviour, poor health outcomes, or both [12]. Global studies indicate that those sentenced for an offence have higher rates of infectious disease, brain injury, and psychiatric disorders than the general population [13]. Additionally, it is more common for this population to experience low educational attainment, low-income levels, substandard housing, and high rates of unemployment [13]. A narrative review was completed with articles published between 1993 and 2014 about social determinants of health data of those in the Canadian prison population [14]. That research indicated that most people in correctional facilities have at least one mental disorder as defined by the Diagnostic and Statistical Manual, though 
exact prevalence rates vary due to a lack of reliable diagnostic activity [14].

To our knowledge, there have not been large scale, generalizable studies conducted on the social determinants of health in psychiatric populations. That is perhaps because service delivery is not centralized, though there is strong evidence that those in lower socioeconomic status groups have higher rates of mental illness [23,24]. There is a gap in the psychiatry literature on understanding how the social determinants of health can influence the need for psychiatric services. As such, a more comprehensive understanding of the complex systems that influence a person's whole socioenvironmental context may contribute to more compassion for the experiences that result in an admission to forensic psychiatry.

Efforts to reduce disparities within and outside of clinical practice can have benefits on longterm health outcomes for those receiving care. However, they can be marred with pragmatic issues. For instance, a study conducted by the Canadian Medical Association in 2014 indicates that many health-care workers feel they have a lack of control over the external factors that lead to poor health outcomes in those they serve [1]. Among those barriers are lack of time and lack of understanding of what concrete steps can be taken. This has been linked to high rates of staff burnout due to feelings of low self-efficacy [1]. How then can health-care institutions and workers address these issues that are difficult to influence within their scope of practice?

\section{Report Objectives}

It is first important to understand how the social determinants of health are distributed across and within people who are admitted to forensic psychiatry. This information can be valuable to highlight trends and needs of this population to inform future goals and strategies. This report is the first attempt to evaluate the social determinants of health in this context.

The purpose of this report is to describe the social determinants of health of those surveyed within an inpatient FPP along a gradient of deprivation. The primary report objectives are:

- Identify, measure, and describe how the social determinants of health are experienced by those admitted to an FPP as presented on initial admission to the program.

- Understand how the social determinants of health are distributed based on an adapted gradient of social and material deprivation.

\section{Methods}

\section{Sampling}

Sixty people who were admitted to an FPP in a major Canadian urban centre were selected using random stratified sampling. These people were sampled from the electronic health records system representing nearly half of the program population. Fifteen people were from each of the two secure and two general inpatient units that comprise this FPP. We did not collect personal identifiable information (e.g., names and casebook numbers).

\section{Materials}

We collected data from the Resident Assessment Instrument-Mental Health (RAI-MH) form. The RAI-MH is a validated assessment tool used to gather information about people who access mental health care [15]. It is typically used at the time of admission, every three months, and at discharge. It collects information related to a person's health, mental health, and demographic variables [15]. It can be completed by physicians, nurses, and select clinicians.

For this review, we gathered data from the initial $\mathrm{RAI}-\mathrm{MH}$ form completed when the person was admitted to the program. Admission data can most accurately represent exposures faced before coming into the program. We collected data from 20 variables most closely related to the social determinants of health outlined by the Canadian Public Health Association [4]. Variables included:

- sex

- race 
- Indigenous status

- educational attainment

- employment status

- source of income

- usual residence status

- residential stability

- marital status

- family visit frequency

- whether person has a support person who is positive toward their discharge into the community

- whether the person lived alone immediately before admission

- who they lived with before admission

- intellectual disability

- self-rated health

- smoking status

- age at first psychiatric admission

- lifetime number of psychiatric admissions

- body mass index (BMI)

- comorbidities (co-occurrence of a medical disorder and mental disorder)

To confirm accuracy, we crosschecked RAI-MH data using chart data. We also used chart data to collect race data and some missing data.

For the secondary, exploratory analysis, we sought to understand how different groups experienced the social determinants of health on a gradient. We grouped people into those who were more or less deprived and used a variation of the Material and Social Deprivation Index (MSDI) [16] to determine categories. The MSDI groups six social factors to understand health inequities in a population based on socioeconomic characteristics. The tool was modified to suit the target population in this report by using similar but more population specific variables. All variables in the dataset were dichotomized (i.e., high school diploma vs. no high school diploma). To understand material deprivation, we grouped employment status, income, and high school diploma achievement into one variable. In a similar approach, we defined social deprivation using marital status, isolation, and whether one had a support person who was positive toward discharge. We then subdivided these variables into two categories: high and low deprivation (see
Table 1: Adapted Material and Social

Deprivation Index (INSPQ, 2019)

\begin{tabular}{|c|c|}
\hline Material deprivation & Variables used \\
\hline $\begin{array}{l}\text { High (most deprived })=0 \\
\text { Low (least deprived })=1\end{array}$ & $\begin{array}{l}\text { High school diploma } \\
\text { achievement (diploma or } \\
\text { no diploma) } \\
\text { Employment status } \\
\text { (employed or unemployed) } \\
\text { Income (income or no } \\
\text { income) }\end{array}$ \\
\hline Social Deprivation & Variables used \\
\hline $\begin{array}{l}\text { High (most deprived })=0 \\
\text { Low (least deprived })=1\end{array}$ & $\begin{array}{l}\text { Marital status (married or } \\
\text { never married) } \\
\text { Isolation (lived alone or } \\
\text { lived with others) } \\
\text { Support (has a person } \\
\text { who is positive toward } \\
\text { discharge or not) }\end{array}$ \\
\hline
\end{tabular}

Table 1). We ran chi-square tests for social and material deprivation separately to determine associations between each original variable in the dataset. We excluded individual variables that were used to create the composite deprivation variables from the tests. For example, because marital status was used to create the social deprivation variable, running a chisquare test on these two variables would yield inflated results, so we excluded it.

\section{Ethics}

Given the project involved evaluation and a needs assessment, it was considered a quality improvement project. As such, the local research ethics board granted a waiver per the TCPS2 (2018) Article 2.5.

\section{Analysis}

We completed the primary analysis by observing frequencies to report on and patterns. We completed the secondary, exploratory analysis using chi-square tests to determine associations between the material and social deprivation categories across all variables described in the primary analysis. All analyses were performed using IBM SPSS version 26. In the data 
Table 2: Demographic Measures $(N=60)$

\begin{tabular}{lrr} 
Variable & $\boldsymbol{n}$ & \% \\
\hline Sex & 7 & 11.7 \\
Female & 53 & 88.3 \\
Male & & \\
Race & 39 & 65.0 \\
White & 13 & 21.7 \\
People of colour & 1 & 1.7 \\
Indigenous & 59 & 98.3 \\
Non-Indigenous & &
\end{tabular}

Mean age of participants was 40 years old.

tables, we omitted information that was not complete in the RAI-MH, inconsistent with the chart, or both. Employment status was missing from 27 cases, race status was missing from eight cases, number of psychiatric admissions was missing from two cases, and usual residence status was missing from one case.

\section{Results}

The final sample size was 60 adults (88.3\% male, $11.7 \%$ female), representing nearly half of the FPP at this centre. Most adults were White (65\%), and all people surveyed spoke English as a first language. One individual identified as Indigenous.

Regarding material-based variables, $45.0 \%$ of people had between a Grade 9 and Grade 12 education. As such, $46.7 \%$ of people were unemployed and not seeking employment, while $56.7 \%$ received income from the Ontario Disabilities Support Program. Also, 61.7\% were admitted from a private dwelling, and $66.7 \%$ had been living in temporary or unstable housing.

With reference to social-based variables, $88.3 \%$ were single and never married. A significant proportion $(40.0 \%)$ had infrequent family contact (i.e., last visited longer than one month ago).

In reviewing frequencies related to health status, $45.0 \%$ of people rated their personal health as excellent. There was a fairly even
Table 3: Material-based Variables $(N=60)$

\begin{tabular}{|c|c|c|}
\hline Variable & $n$ & $\%$ \\
\hline \multicolumn{3}{|l|}{ Highest educational attainment } \\
\hline No schooling & 17 & 28.3 \\
\hline Grade 8 or less & 5 & 8.3 \\
\hline Grade 9 to 11 & 13 & 21.7 \\
\hline High school diploma & 14 & 23.3 \\
\hline Technical or trade school & 1 & 1.7 \\
\hline Some college or university & 7 & 11.7 \\
\hline College diploma or university degree & 1 & 1.7 \\
\hline \multicolumn{3}{|l|}{ Employment status } \\
\hline Employed & 2 & 3.3 \\
\hline Unemployed, seeking & 3 & 5.0 \\
\hline Unemployed, not seeking & 28 & 46.7 \\
\hline \multicolumn{3}{|l|}{ Source of income } \\
\hline Employment & 2 & 3.3 \\
\hline Ontario Disabilities Support Program & 34 & 56.7 \\
\hline Social assistance (unspecified) & 7 & 11.7 \\
\hline Disability insurance & 5 & 8.3 \\
\hline No income & 8 & 13.3 \\
\hline \multicolumn{3}{|l|}{ Usual residence status } \\
\hline $\begin{array}{l}\text { Private home, apartment, or rented } \\
\text { room }\end{array}$ & 37 & 61.7 \\
\hline Board and care & 1 & 1.7 \\
\hline Mental health residence & 3 & 5.0 \\
\hline Group home & 2 & 3.3 \\
\hline Psychiatric hospital or unit & 13 & 21.7 \\
\hline Homeless & 2 & 3.3 \\
\hline Correctional facility & 1 & 1.7 \\
\hline \multicolumn{3}{|l|}{ Residential stability } \\
\hline Residence was temporary & 40 & 66.7 \\
\hline Residence was not temporary & 20 & 33.3 \\
\hline
\end{tabular}

distribution of smokers and nonsmokers. A total of $61.7 \%$ of people were first admitted to a psychiatric hospital between the ages of 15 and 24 years, moreover $61.7 \%$ had four or more psychiatric admissions in their lifetime. Additionally, $76.6 \%$ of people were classified as either overweight or obese at the time of admission. Finally, $53.3 \%$ had one more or chronic disease(s) excluding their mental illness. 
Table 4: Social-based Variables $(N=60)$

\begin{tabular}{lrr} 
Variable & $\boldsymbol{n}$ & $\%$ \\
\hline Marital status & 53 & 88.3 \\
Never married & 3 & 5.0 \\
Married & 2 & 3.3 \\
Separated & 2 & 3.3 \\
Divorced & \multicolumn{2}{c}{} \\
Family visit occurred & 17 & 28.3 \\
Within last 3 days & 7 & 11.7 \\
Within last week (more than 3 days & & \\
ago) & 12 & 20.0 \\
Within last month (not within last & & \\
week) & 24 & 40.0 \\
More than one month ago & 26 & 43.3 \\
Has support person who is positive toward discharge \\
Yes & 34 & 56.7 \\
No & 32 & 53.3 \\
Who lived with immediately before admission & \\
Lived alone & 28 & 46.7 \\
\hline Lived with others & &
\end{tabular}

\section{Material and Social Deprivation}

Results from the exploratory association tests found some significance, but overall trends were most notable. Regarding material deprivation, there was a significant association with race $(p=0.044)$. White people appeared to be disproportionately deprived in this sample.

As seen in Table 6, while intellectual disability yielded a small sample size, every person who was identified to have an intellectual disability was categorized as materially deprived $(p=$ $0.103)$. Most marked is the association between comorbidity status (that is a co-occurrence of a medical disorder and mental disorder) and material deprivation. There were more people with a comorbidity who were also materially deprived $(p=0.051)$.

When seeking associations for social deprivation, there were no statistically significant findings (See Table 7). However, a cursory review suggested trends. Every person with an intellectual disability also fell into the social deprivation group, albeit not statistically significant.
Table 5: Health Status $(N=60)$

\begin{tabular}{|c|c|c|}
\hline Variable & $n$ & $\%$ \\
\hline \multicolumn{3}{|l|}{ Intellectual disability } \\
\hline Yes & 5 & 8.3 \\
\hline No & 55 & 91.7 \\
\hline \multicolumn{3}{|l|}{ Self-rated health } \\
\hline Excellent & 27 & 45.0 \\
\hline Good & 20 & 33.3 \\
\hline Fair & 9 & 15.0 \\
\hline Poor & 4 & 6.7 \\
\hline \multicolumn{3}{|c|}{ Smoking or chewing tobacco use } \\
\hline No & 34 & 56.7 \\
\hline Yes & 26 & 43.3 \\
\hline \multicolumn{3}{|c|}{ Age at first psychiatric admission, years } \\
\hline $0-14$ & 4 & 6.7 \\
\hline $15-24$ & 37 & 61.7 \\
\hline $25-44$ & 14 & 23.3 \\
\hline $45-64$ & 5 & 8.3 \\
\hline \multicolumn{3}{|c|}{ Number of psychiatric admissions (lifetime) } \\
\hline $1-3$ & 21 & 35.0 \\
\hline $4-5$ & 13 & 21.7 \\
\hline 6 or more & 24 & 40.0 \\
\hline \multicolumn{3}{|l|}{ Body mass index } \\
\hline Average (18.5-24.9) & 13 & 21.7 \\
\hline Underweight (<18.5) & 1 & 1.7 \\
\hline Overweight (25-29.9) & 14 & 23.3 \\
\hline Obese $(\geq 30)]$ & 32 & 53.3 \\
\hline \multicolumn{3}{|c|}{ Comorbidities (diseases excluding mental illness) } \\
\hline$\geq 1$ chronic disease $(\mathrm{s})$ & 32 & 53.3 \\
\hline$\geq 1$ disease risk factors & 2 & 3.3 \\
\hline No comorbidities & 26 & 43.3 \\
\hline
\end{tabular}

While again not statistically significant, a higher number of those who were socially deprived were first admitted between the ages of 15 and 24 years. More people with comorbidities fell into the social deprivation group, which is a notable trend.

\section{Discussion}

The framework created by this article can facilitate an understanding of preadmission factors that may impact health, provide a broader understanding to caregivers, instruct 
Table 6: Associations Between Material Deprivation and Each Variable

\begin{tabular}{lrr} 
Variable & $\mathbf{X}^{2}$ & $\boldsymbol{p}$ \\
\hline Ethnicity & 4.042 & 0.044 \\
Marital status & 0.008 & 0.930 \\
Housing & 0.318 & 0.573 \\
Residential stability & 1.335 & 0.248 \\
Family visits & 0.629 & 0.428 \\
Social support & 0.008 & 0.927 \\
Isolation & 0.356 & 0.551 \\
Intellectual disability & 2.664 & 0.103 \\
Self-rated health & 0.153 & 0.696 \\
Smoking status & 0.092 & 0.761 \\
Age at first admission & 2.759 & 0.430 \\
Number of admissions & 0.440 & 0.834 \\
Overweight or obese & 0.910 & 0.763 \\
Comorbidities & 3.819 & 0.051 \\
\hline
\end{tabular}

and guide treatment, and inform healthy public policy.

\section{Primary Analysis}

We compared the findings from the primary analysis with comparable data in the Canadian prison and general populations. The prison population is an appropriate comparison group given that people in an FPP are either admitted from a correctional facility or may avoid imprisonment secondary to criminal nonresponsibility to participate in comprehensive treatment program within a hospital context. We made efforts to bridge recommendations from the broader comparison group as it applied to an FPP, as well as to the general population to reduce risk factors that may lead to admission to an FPP.

Consistent with the literature, most people in this report were first admitted to a psychiatric hospital between the ages of 15 and 24 years. In the Canadian population, people in this age group are most likely to experience mental illness, substance use disorders, or both $[17,18]$. This suggests public health strategies to prevent mental illness should address those who
Table 7: Associations Between Social Deprivation and Each Variable

\begin{tabular}{lrr} 
Variable & $\mathbf{X}^{2}$ & $\boldsymbol{p}$ \\
\hline Ethnicity & 0.308 & 0.579 \\
Education & 0.988 & 0.320 \\
Employment status & 1.770 & 0.674 \\
Income & 1.140 & 0.286 \\
Housing & 0.057 & 0.812 \\
Residential stability & 0.657 & 0.418 \\
Family visits & 1.108 & 0.293 \\
Intellectual disability & 2.156 & 0.142 \\
Self-rated health & 0.048 & 0.826 \\
Smoking status & 1.827 & 0.171 \\
Age at first admission & 3.664 & 0.300 \\
Number of admissions & 0.764 & 0.382 \\
Overweight or obese & 0.268 & 0.605 \\
Comorbidities & 1.166 & 0.280 \\
\hline
\end{tabular}

are younger than 15 years of age. In this context, efforts at identifying those at risk need to occur at an earlier age. We suggest that health policies include greater mental health resources in schools, in common gathering places (such as not-for-profit community service organizations), and in areas with greater levels of social and economic deprivation.

Education is an important health indicator as positive associations are found between good health and higher education in the Canadian population [19]. People in this report showed low educational attainment as $58.3 \%$ did not complete high school. This is similarly reflected in the Canadian correctional population, where 46.1\% have between a Grade 10 and Grade 12 education [20]. High educational attainment is correlated with better health as those in higher education groups are more likely to engage in healthy behaviours, such as exercise [21]. As such, hospitals and governments at the municipal, provincial, territorial, and federal levels need to support efforts to provide opportunities for people in an FPP.

Race and ethnicity proportions differed from the Canadian prison population. In our sample, 
$65 \%$ of people were White, and one individual was identified to be an Indigenous person. In the Canadian provincial and territorial correctional population combined, $52 \%$ are White and $28 \%$ are Indigenous [20]. A review of available resources for Indigenous individuals and people of colour is imperative considering the disproportionate representation in the legal system, including forensic psychiatry. Accessibility of the program to Black, Indigenous and all people of colour must be considered to ensure that FPP services are available to all groups, especially those most represented in the Canadian prison population [20]. An understanding of racism and race-based inequities, colonial histories, trauma, and disproportionate access to social resources are critical if current trends in health inequity are to change. The Ontario Ministry of Health and Long-Term Care has developed a Health Equity Impact Assessment Tool that can be used to understand how a program can maximize positive impacts and minimize negative impacts on specific population groups [22].

\section{Secondary Analysis}

Health status findings suggest that the sample population is vulnerable to disease and disease risk factors. A review of health status is important to understand given how the social determinants of health can disproportionately affect a person's health.

A large proportion of people in this evaluation were overweight or obese at the time of admission $(76.6 \%)$. This is consistent with the literature, which also indicates people in forensic programs are likely to gain weight during their stay. One such study conducted in Canada in 2010 found that in a one-year period, $40.0 \%$ of people in an FPP increased their weight by at least 1 BMI [6]. Given cardiovascular disease and other chronic diseases are closely related to obesity, weight management education and programming, in addition to access to healthy foods and opportunity for physical activity, may be important for people in programs like an FPP. Because health status can impact a person's ability to function in society, for example their ability to gain and maintain long-term employment, it is an important consideration.

Those who had a comorbidity were more materially deprived than those who were not. This finding highlights the potency of the environment in influencing disease outcomes. It suggests individual responsibility to improving health alone may not be as powerful as also providing a more comprehensive approach that encompasses wider environmental health influencers. This is consistent with the literature, which indicates a social gradient in health outcomes influenced by unstable employment, poverty, and lack of social support [2]. Those with a mental illness are particularly impacted by poor health as reflected in their life expectancy, which is 10 to 20 years shorter than that of the general population [23]. Given those in the lowest income group in Canada are three to four times more likely to report fair or poor mental health than those in the highest income group [24], health may be improved by recognizing mental illness and poor health as social issues much sooner combined with a comprehensive and targeted program of key interventions.

\section{Limitations}

There are some limitations of this report to be mentioned. First, we collected data based on information entered by different staff at different points in time. Some information was missing. Future studies might gather this information in real time by one program evaluator.

Additionally, the stratified goal-directed sample may not be representative of the entire population and may be limited in its generalizability to other forensic programs. Given the small sample size in each stratum, random sampling software was not used. Using the entire FPP population available at this centre may have yielded more generalizable results. Sample size may have limited the ability to find associations in deprivation groups.

Data may have been lost in the dichotomous coding of variables used to create the population specific deprivation index. 
Future studies could perform analysis using multivariate tests of association and odds ratios, which may provide information on associations as this report used a correlational test. Further, having a reference population could reveal interesting findings for comparison. Other studies might seek to include first-hand experiences through in-person interviews, which was limited in this report by COVID-19 related restrictions.

\section{Implications}

Findings from this report can be used to inform current clinical practice and organizational structures. It would be important for the program to understand and act on any access barriers, broaden multisectorial collaboration, enhance staff understanding of the social determinants of health and health equity concepts. Programs should also develop tools to ensure people's needs are being met from a social determinant of health perspective, from admission through to discharge.

There is a need to understand how institutional structures might pose access barriers to Black, Indigenous, and all people of colour. This understanding can apply a multisectorial approach to understand how a person moves into an FPP from their initial point of entry to the justice system. The Health Equity Impact Assessment [22] tool can be applied, and outcomes can be explored with the prison and mental health sectors to ensure those with the greatest need are able to access the highly beneficial services offered through an FPP.

Given the secondary exploratory findings of this report show that people in the program are socially and materially deprived, increased staff education on the social determinants of health and health equity is important. This education may improve empathy in practice as people admitted to the program can be understood as making choices within a broader social context rather than existing in a vacuum. Because the social determinants of health have a higher impact on a person's health than health interventions alone [3], a focus on altering a person's socioenvironmental context before discharge may result in improved health outcomes and lower re-admission rates.

In addition, while the RAI-MH provides rich data relative to the social determinants of health, a program-specific tool could be developed to capture all areas outlined by the Canadian Public Health Association. Information could be carried from intake to discharge to ensure all social determinant of health needs are met when a person leaves the program.

\section{Conclusion}

This report generated additional information on the social determinants of health in a sample people in an FPP. It highlights how poor social determinants of health are distributed on a social gradient. The knowledge presented may inform health-care practices, as well as policy that seeks to apply an upstream approach to minimize factors leading to the co-occurrence of mental illness and criminal activity. A multisectorial approach that seeks to reduce population-level mental illness exposures is needed.

Further, training health-care professionals to identify social challenges more easily can assist in improving quality of care. Knowledge of the social determinants of health can help health-care professionals develop a more comprehensive understanding of the people they support.

While it may seem difficult to address wide social issues as individuals, health-care professionals have a strong skillset with which to advocate for social change. Clinicians can connect people with tailored community resources and form partnerships beyond the health-care system. Collaborations can be made with multiple sectors, such as community groups, public health, and local leaders [1]. Healthcare workers can model empathy and combat stigma by educating those around them and seeing those they support as people first. The combined voices of people experiencing mental illness, health-care workers, and their institutions will be important drivers of change. 


\section{References}

1. Andermann A. Taking action on the social determinants of health in clinical practice: a framework for health professionals. Canadian Medical Association Journal. 2016.;188(17-18):E474-E483. https://doi.org/10.1503/cmaj.160177.

2. Wilkinson R, Marmot M (eds.) Social determinants of health: The solid facts (2nd ed.). Denmark: World Health Organization; 2003. https://www.euro.who.int/_data/assets/ pdf_file/0005/98438/e81384.pdf

3. World Health Organization. Social determinants of health. 2020. https://www.who.int/social_determinants/ sdh_definition/en/.

4. Canadian Public Health Association. What are the social determinants of health? n.d. https://www.cpha.ca/ what-are-social-determinants-health.

5. Pickett KE, Wilkinson RG. Inequality: An underacknowledged source of mental illness and distress. British Journal of Psychiatry. 2010;197(6):426-428. https://doi.org/10.1192/bjp.bp.109.072066.

6. Hilton NZ, Ham E, Lang C, Harris, GT. Weight gain and its correlates among forensic inpatients. Canadian Journal of Psychiatry. 2015;60(5):232-238. https://doi.org/10.1177/070674371506000505.

7. Scerri A, Innes A, Scerri C. Person-centred dementia care in acute hospital wards-The influence of staff knowledge and attitudes. Geriatric Nursing. 2020;41(3):215-221. https:// doi.org/10.1016/j.gerinurse.2019.09.001.

8. Andresen R, Oades LG, Caputi P. Psychological recovery: Beyond mental illness. Chichester, West Sussex: WileyBlackwell; 2011.

9. Oliver ME. The psychology of criminal conduct (fifth edition) edited by D.A. Andrews and J. Bonta [book review]. British Journal of Psychology. 2011;102(3):689-690.https://doi. org/10.1111/j.2044-8295.2011.02057.x.

10. MacPhail A, Verdun-Jones S. Mental illness and the criminal justice system. Vancouver,
British Columbia: International Centre for Criminal Law Reform and Criminal Justice Policy; 2013. https://icclr.org/wp-content/ uploads/2019/06/Mental-IIIness-and-theCriminal-Justice-System-Final-VS.pdf?x96127.

11. Hiday VA. Putting community risk in perspective: A look at correlations, causes and controls. International Journal of Law and Psychiatry. 2006;29(4):316-331. https://doi.org/10.1016/j.ijlp.2004.08.010.

12. Trotter RT, Lininger MR, Camplain R, Fofanov VY, Camplain C, Baldwin JA. A survey of health disparities, social determinants of health, and converging morbidities in a county jail: A cultural-ecological assessment of health conditions in jail populations. International Journal of Environmental Research and Public Health. 2018;15(11):2500. https://doi.org/10.3390/ijerph15112500.

13. Stewart LA, Nolan A, Thompson J, Power J. Social determinants of health among Canadian inmates. International Journal of Prisoner Health. 2018;14(1):4-15. https://doi.org/10.1108/lJPH-08-2016-0038.

14. Kouyoumdjian F, Schuler A, Matheson FI, Hwang, SW. Health status of prisoners in Canada: Narrative review. Canadian Family Physician. 2016;62(3):215-222. https://www.cfp.ca/content/62/3/215.

15. Canadian Institute for Health Information. Ontario mental health reporting system metadata. 2019. https://www.cihi.ca/en/ ontario-mental-health-reporting-systemmetadata.

16. Institut national de santé publique du Québec. Material and social deprivation index. 2019. https://www.inspq.qc.ca/en/deprivation/ material-and-social-deprivation-index.

17. Pearson C, Janz T, Ali J. Mental and substance use disorders in Canada. Statistics Canada Catalogue no. 82-624-X. 2013. https://www150.statcan.gc.ca/n1/pub/82624-x/2013001/article/11855-eng.pdf.

18. Statistics Canada. Table 13-10-0394-01 Leading causes of death, total population, by age group. https://www150.statcan.gc.ca/t1/ tbl1/en/tv.action?pid=1310039401. 
19. Heger D. Decomposing differences in health and inequality using quasi-objective health indices. Applied Economics.

2018;50(26):2844-2859. https://doi.org/10.108 0/00036846.2017.1412073.

20. Zinger I. Office of the Correctional Investigator annual report 2018-2019. 2019.

https://oci-bec.gc.ca/cnt/rpt/annrpt/ annrpt20182019-eng.aspx.

21. Hajizadeh M, Mitnitski A, Rockwood K. Socioeconomic gradient in health in Canada: Is the gap widening or narrowing? Health Policy. 2016;120(9):1040-1050.

https://doi.org/10.1016/j. healthpol.2016.07.019.

22. Ontario Ministry of Health and Long-Term Care. HEIA: Health equity impact assessment.
2020. https://www.health.gov.on.ca/en/pro/ programs/heia/.

23. Chesney E, Goodwin GM, Fazel S. Risks of all-cause and suicide mortality in mental disorders: A meta-review. World Psychiatry. 2014;13:153-160.

https://doi.org/10.1002/wps.20128.

24. Mawani FN, Gilmour H. Validation of self-rated mental health. Statistics Canada Catalogue no. 82-003-X. 2010. https://www150.statcan.gc.ca/n1/en/ catalogue/82-003-X201000311288.

\section{Corresponding author}

Samantha Perrotta, Department of Health Aging and Society, McMaster University, Kenneth Taylor Hall Room 226, 1280 Main Street West, Hamilton, ON L8S 4M4 Canada - email: perros2@mcmaster. 